\title{
Evaluation of efficacy and tolerability of eperisone and thiocolchicoside in treatment of low back pain associated with muscle spasm: An open label, prospective, randomized controlled trial
}

\author{
Syed H. Maaz ${ }^{1}$, Prakash N. Khandelwal ${ }^{2}$, Shiraz M. Baig ${ }^{2}$, Sudhakar M. Doifode $^{2}$, \\ Ulhas M. Ghotkar ${ }^{3}$
}

\begin{abstract}
${ }^{1}$ Department of Pharmacology, Indian Institute of Medical Science and Research, Jalna, Maharashtra, India

${ }^{2}$ Department of Pharmacology, Government Medical College, Aurangabad, Maharashtra, India ${ }^{3}$ Department of Pharmacology, Government Medical College, Akola, Maharashtra, India
\end{abstract}

Received: 07 October 2016 Accepted: 03 November 2016

\section{*Correspondence to: \\ Dr. Syed H. Maaz, \\ Email: dr_maaz_syed@ yahoo.com}

Copyright: (C) the author(s), publisher and licensee Medip Academy. This is an openaccess article distributed under the terms of the Creative Commons Attribution NonCommercial License, which permits unrestricted noncommercial use, distribution, and reproduction in any medium, provided the original work is properly cited.

\begin{abstract}
Background: Low back pain has a high prevalence in adult population. Because of reflex muscle spasm, muscle relaxants are frequently used either alone or in combination with analgesics. Eperisone inhibits voltage gated sodium channels in brain stem and Thiocolchicoside acts via GABA-mediated mechanism to relax muscle spasm and relieves pain.

Methods: This was a prospective; open labeled, randomized, two-arm, parallel group, controlled, clinical trial. 113 patients were randomised to two groups. Patients in group A received Tablet Eperisone $100 \mathrm{mg}$ whereas patients in group B received Tablet Thiocolchicoside $8 \mathrm{mg}$ for seven days along with Tablet Paracetamol $500 \mathrm{mg}$. The outcome measures of trial were the improvement in finger to floor distance (FFD) and pain in lumbar region, relief of spasm and tenderness of paravertebral muscles on day 4 and 7.

Results: At the end of the study FFD reduced by $18 \mathrm{~cm}$ in group A (p < $\left.0.0001^{*}\right)$ and $17.36 \mathrm{~cm}$ in group $\mathrm{B}\left(\mathrm{p}<0.0001^{*}\right)$ from baseline. Mean score of pain on day 7 reduced by 5.64 scale in group A as compared to 5.42 scale in group B ( $<<0.0001^{*}$ in both groups). Paravertebral tenderness reduced by $92.6 \%$ in group A and $94.6 \%$ in group B at the end of the trial. On day 7 , the spasm relief was $87 \%$ in group A and $88 \%$ in group B.

Conclusions: Eperisone is an effective muscle relaxant with equivalent efficacy compared to Thiocolchicoside, and has a better tolerability in treatment of low back pain with muscle spasm.
\end{abstract}

Keywords: Eperisone, Low back pain, Thiocolchicoside

\section{INTRODUCTION}

Muscle spasm is sustained and painful involuntary contraction. ${ }^{1}$ Musculoskeletal diseases associated with painful muscle spasm particularly low back pain has a high prevalence. ${ }^{2}$ Low back pain is considered to be the result of a self-perpetuating cycle of pain and spasm. ${ }^{2,3}$ It has annual incidence of $10-15 \%$ and a point prevalence of $15-30 \%$ in adult population. ${ }^{4}$ Low back pain is the most common cause of activity limitation in people younger than 45 years and second most common symptom related reason for visits to a physician. ${ }^{5}$ The involvement of reflex muscle spasms leads to the frequent use of muscle relaxants, either alone or in combination with analgesics. ${ }^{6}$ Muscle relaxants and non-steroidal anti-inflammatory drugs (NSAID) both categories have therapeutic utility in management of painful muscle spasms. ${ }^{7}$ Development of sedation seems to be the limiting factor in the use of muscle relaxants for treatment, as they can affect daily activity and decrease working capability. 8,9 When voltage-gated sodium channels (VGSC) are blocked, it results in inhibition of neural activity and pain sensation. So VGSC remain viable targets for the development of novel analgesics. ${ }^{10}$ Eperisone is a centrally acting muscle 
relaxant that inhibits VGSC in the brain stem. ${ }^{10,11}$ It inhibits mono and multi synaptic spinal reflexes. ${ }^{11,12}$ Eperisone acts as an analgesic apart from being a muscle relaxant. ${ }^{13}$ It is also considered to be less sedative muscle relaxant. ${ }^{14,15}$ Thiocolchicoside (TCC) is a semi synthetic derivative from colchicoside. It acts via GABA-mediated mechanism to relax muscle spasm and relieve pain. ${ }^{8}$ Hence this study was conducted to compare and evaluate the efficacy and tolerability of two non-sedative muscle relaxants, Eperisone and Thiocolchicoside in combination with Paracetamol, in patients suffering from painful muscle spasms associated with low back pain.

\section{METHODS}

This was a prospective, open labelled, randomized, twoarm, parallel group, controlled, clinical trial. It was conducted in compliance with the protocol, after Institutional Ethics Committee (IEC) approval, informed consent regulations, as per Declaration of Helsinki, ICH good Clinical Practice (GCP) guidelines and the ICMR guidelines for Biomedical Research on Human Subjects, 2006. Patients presenting with low back pain associated with skeletal muscle spasms attending the outpatient department (O.P.D.) of orthopaedics of a tertiary health care centre in Aurangabad from June 2013 to June 2014.

Patients of either gender between 18 to 55 years of age with acute musculoskeletal spasm associated with low back pain, as diagnosed by the orthopaedic surgeon, were included in the trial. All patients provided written, vernacular, witnessed, informed consent to participate in the trial. Patients with any abnormality other than the inclusion criteria seen by orthopaedic surgeon, patients treated with any other muscle relaxants, opioids, analgesics within one week prior to the trial or willing to continue to receive these drugs as concomitant medication during the trial period were excluded. Patients with known hypersensitivity to test or comparator medicine, history of significant hepatic, cardiac, renal and inflammatory bowel disease were excluded. Pregnant or lactating mothers were also not included in the trial.

\section{Methodology}

All patients willing to participate and give an informed consent were screened for eligibility. Baseline evaluation included recording of demographic details, medical history, general and systemic examination, and laboratory investigations, which included complete haemogram, hepatic and renal function tests and routine urine analysis.

The eligible patients were enrolled and randomized, by a computer generated randomization sequence, into two treatment groups. Patients in group A received Tablet Eperisone $100 \mathrm{mg}$ thrice a day whereas patients in group $\mathrm{B}$ received Tablet Thiocolchicoside $8 \mathrm{mg}$ twice a day for seven days. Patients in both the groups also received Tablet Paracetamol $500 \mathrm{mg}$ thrice a day for seven days in addition to the trial medication. The patients were allowed to take Tablet Aceclofenac $100 \mathrm{mg}$ as a rescue medication whenever the pain was unbearable. The patients were provided with diary and instructed to carefully record details of any adverse event or use of rescue medication. All patients were followed up for efficacy and safety assessment on day 4 and 7. (Fig 1)

The efficacy assessment included evaluation of severity of low back pain using FFD, paravertebral tenderness and visual analogue scale (VAS) for lumbar pain, and spasm. The safety was evaluated objectively by visual and auditory reaction time and sedation as measured on VAS. Any spontaneously reported adverse event was recorded in the standard format of ADR reporting. The FFD was evaluated by asking the patients to bend forward and try to touch the floor with fingers; the distance between fingers and ground (hand to floor) was measured by means of a ruler in centimetres. Improvement in lumbar pain was assessed on VAS (Score 0-10) with 0 representing 'no pain' and 10 representing 'severe intolerable pain'. Relief of spasm was assessed using VAS score (Score $0-10$ ) as: $0=$ no spasm relief, $<4=$ mild relief of spasm, 4.1- $7=$ moderate relief of spasm, 7.1-9 = nearly complete relief of spasm, 9.1- $10=$ complete spasm relief. Improvement in tenderness of paravertebral muscles was graded as, $0=$ no pain on firm pressure, $1=$ slight pain on firm pressure, $2=$ moderate pain on moderate pressure, $3=$ severe pain on slight touch. The patients were explained the procedure of evaluation of safety parameters. Reaction time test was performed for assessing the auditory and visual response using reaction time apparatus. Sedation was calculated using a VAS (Score 0-10) on day 0 and 7 where $0=$ no sedation, $1-3=$ mild sedation, $4-7=$ moderate sedation, and $8-10=$ high sedation. Haematological and serological investigations were done before and after the trial.

\section{Efficacy parameters}

Primary outcome measure of the trial was the improvement in FFD from baseline on day 4 and 7 and secondary outcome measures were improvement in pain in lumbar region, relief of spasm and tenderness of paravertebral muscles.

\section{Safety parameters}

Visual and auditory reaction time and VAS score of the sedation were used as safety parameters.

\section{Statistical analysis}

All the data was entered into Microsoft Excel from case record form for analysis. For comparing quantitative data within the study groups Students Paired't' test and repeated measures ANOVA were used and for comparing quantitative data between the study groups Students Unpaired ' $t$ ' test were applied. Comparison of qualitative data between the study groups was done using Fisher's 
exact test. Statistical analysis was performed with the help of the software 'Graph pad Prism 5'. The p value of $<0.05$ was considered as statistically significant.

\section{RESULTS}

Total of 135 patients with acute low back pain were screened, and 113 eligible patients were randomized equally into two treatment groups. In group A 6 patients and in group B 7 patients were lost to trial. Both the groups were similar in demographic profile at baseline as shown in table 1 . Both the groups showed significant reduction in all efficacy parameters (Table 2). FFD in group A reduced by $33.52 \%$ and $70.15 \%$ on day 4 and day 7 respectively while in group B it reduced to $35.21 \%$ on day 4 and $69.51 \%$ on day 7 . VAS score of pain on day 4 was decrease by $49 \%$ in group A and $47 \%$ in group B and on day 7 it was decrease by $87 \%$ and $85 \%$ in group A and B respectively. Paravertebral tenderness in group A reduced by $67 \%$ and $92.6 \%$ on day 4 and day 7 respectively while in group B it reduced to $69 \%$ on day 4 and $94.6 \%$ on day 7 .
Table 1: Baseline characteristics in study groups.

\begin{tabular}{|lll|l|}
\hline Parameter & $\begin{array}{l}\text { Group A } \\
(\mathbf{n = 5 0 )} \\
\text { EPN }+ \\
\text { PCM }\end{array}$ & $\begin{array}{l}\text { Group B } \\
(\mathbf{n = 5 0 )} \\
\text { TCC + } \\
\text { PCM }\end{array}$ & $\begin{array}{c}\text { 'P' } \\
\text { value }\end{array}$ \\
\hline Age in years & $\begin{array}{l}43.50 \pm \\
7.35\end{array}$ & $\begin{array}{l}45.32 \pm \\
6.72\end{array}$ & $0.2038^{\dagger}$ \\
\hline $\begin{array}{l}\text { Men } \\
\text { Gender }\end{array}$ & 23 & 21 & $0.8405^{\dagger}$ \\
\hline $\begin{array}{l}\text { Women } \\
(\mathrm{n})\end{array}$ & 27 & 29 & \\
\hline $\begin{array}{l}\text { Finger to Floor } \\
\text { distance (cm) }\end{array}$ & $25.66 \pm 2.27$ & $24.88 \pm 2.53$ & $0.3690^{\dagger}$ \\
\hline $\begin{array}{l}\text { VAS score of } \\
\text { Pain }\end{array}$ & $6.52 \pm 0.83$ & $6.38 \pm 1.02$ & $0.5938^{\dagger}$ \\
\hline $\begin{array}{l}\text { Paravertebral } \\
\text { Tenderness score }\end{array}$ & $1.62 \pm 0.52$ & $1.48 \pm 0.50$ & $0.2160^{\dagger}$ \\
\hline
\end{tabular}

EPN: Eperisone, TCC: Thiocolchicoside, PCM: Paracetamol, SD: Standard deviation, VAS: Visual Analogue Scale, n: Numbers; Values: Mean \pm SD (otherwise mentioned); *: Statistically significant, $\dagger$ : Using 2-tailed unpaired t-test, Using Fisher's exact test.

Table 2: Efficacy assessment.

\begin{tabular}{|c|c|c|c|c|}
\hline No. & Parameter & $\begin{array}{l}\text { Group A EPN + PCM } \\
(\text { Mean } \pm \text { SD })\end{array}$ & $\begin{array}{l}\text { Group B TCC + PCM } \\
(\text { Mean } \pm \text { SD })\end{array}$ & $\mathbf{P}$ value inter group \\
\hline 1 & $\begin{array}{l}\text { Mean FFD in centimeter } \\
\text { Day } 0 \\
\text { Day } 4 \\
\text { Day } 7 \\
\text { P value intragroup } \\
\S\end{array}$ & $\begin{array}{l}25.66 \pm 2.27 \\
17.06 \pm 1.98 \\
07.66 \pm 0.84 \\
<0.0001^{*}\end{array}$ & $\begin{array}{l}24.88 \pm 2.53 \\
16.12 \pm 1.67 \\
7.52 \pm 0.75 \\
<0.0001^{*}\end{array}$ & $\begin{array}{l}0.3690 \\
0.0704 \\
0.3898\end{array}$ \\
\hline 2 & $\begin{array}{l}\text { Mean Pain score on VAS } \\
\text { Day } 0 \\
\text { Day } 4 \\
\text { Day } 7 \\
\text { P value intragroup } \\
\text { § }\end{array}$ & $\begin{array}{l}6.52 \pm 0.83 \\
3.34 \pm 1.01 \\
0.88 \pm 0.59 \\
<0.0001^{*}\end{array}$ & $\begin{array}{l}6.38 \pm 1.02 \\
3.42 \pm 1.00 \\
0.96 \pm 0.56 \\
<0.0001^{*}\end{array}$ & $\begin{array}{l}0.5938 \\
0.6960 \\
0.7009\end{array}$ \\
\hline 3 & $\begin{array}{l}\text { Mean Tenderness score } \\
\text { Day } 0 \\
\text { Day } 4 \\
\text { Day } 7 \\
\text { P value intragroup } \\
\text { § }\end{array}$ & $\begin{array}{l}1.62 \pm 0.52 \\
0.54 \pm 0.50 \\
0.12 \pm 0.32 \\
<0.0001^{*}\end{array}$ & $\begin{array}{l}1.48 \pm 0.50 \\
0.46 \pm 0.50 \\
0.08 \pm 0.27 \\
<0.0001^{*}\end{array}$ & $\begin{array}{l}0.2160 \\
0.5723 \\
0.8452\end{array}$ \\
\hline 4 & $\begin{array}{l}\text { Mean Spasm relief on VAS } \\
\text { Day } 4 \\
\text { Day } 7 \\
\text { P value intragroup } \\
\S\end{array}$ & $\begin{array}{l}6.26 \pm 0.59 \\
8.82 \pm 0.65 \\
<0.0001 *\end{array}$ & $\begin{array}{l}6.34 \pm 0.68 \\
8.92 \pm 0.82 \\
<0.0001 *\end{array}$ & $\begin{array}{l}0.5812 \\
0.5307\end{array}$ \\
\hline
\end{tabular}

EPN: Eperisone, TCC: Thiocolchicoside, PCM: Paracetamol, SD: Standard deviation, VAS: Visual Analogue Scale, n: Numbers; Values: Mean \pm SD (otherwise mentioned); *: Statistically significant, $\uparrow$ : Using 2-tailed unpaired t-test, $\S$ : Repeated measure ANOVA.

None of the efficacy parameters showed any statistically significant difference between the two treatment groups at day 4 or 7 (Table 2). None of the safety parameters showed any statistically significant difference between the two treatment groups at baseline or day 7 (Table 3). Laboratory investigations did not show any significant change in both the groups before and after the completion of study. None of the patients required any rescue medication in either of the groups. Adverse effects were reported in six patients (12\%) from group A as compared to 12 patients (24\%) from group B (Table 4). No serious ADRs were reported in any of the groups. 


\section{DISCUSSION}

In most patients, low back pain is nonspecific and cannot be reliably attributed to a specific condition or abnormality in the back. ${ }^{16}$ The goals of pharmacological intervention for acute low back pain is, not only the relief of pain, but also the reduction of muscle spasm and inflammation. ${ }^{16,17}$ Muscle relaxants exert their pharmacological effects at the level of spinal cord, brainstem, cerebrum, and muscle fibre. Their centrally mediated mechanism of action can exert a clinically significant peripheral therapeutic effect. ${ }^{18}$ The addition of a skeletal muscle relaxant to Paracetamol or other nonsteroidal anti-inflammatory drugs (NSAID) may be more effective than the analgesic alone. ${ }^{19,20}$

Table 3: Safety assessment.

\begin{tabular}{|c|c|c|c|c|}
\hline No. & Parameter & $\begin{array}{l}\text { Group A EPN + PCM } \\
(\text { Mean } \pm \text { SD })\end{array}$ & $\begin{array}{l}\text { Group B TCC + PCM } \\
(\text { Mean } \pm \text { SD })\end{array}$ & $\begin{array}{l}\text { P value inter } \\
\text { group }^{\dagger}\end{array}$ \\
\hline \multirow[t]{2}{*}{1} & $\begin{array}{l}\text { Score of Visual reaction time } \\
\text { Day } 0 \\
\text { Day } 7\end{array}$ & $\begin{array}{l}0.778 \pm 0.124 \\
0.792 \pm 0.124\end{array}$ & $\begin{array}{l}0.780 \pm 0.124 \\
0.794 \pm 0.123\end{array}$ & \multirow[t]{2}{*}{$\begin{array}{l}0.9334 \\
0.9892\end{array}$} \\
\hline & $P$ value intragroup & 0.2762 & 0.2774 & \\
\hline \multirow[t]{2}{*}{2} & $\begin{array}{l}\text { Score of Auditory reaction time } \\
\text { Day } 0 \\
\text { Day } 7\end{array}$ & $\begin{array}{l}0.726 \pm 0.127 \\
0.733 \pm 0.108\end{array}$ & $\begin{array}{l}0.730 \pm 0.124 \\
0.741 \pm 0.113\end{array}$ & \multirow[t]{2}{*}{$\begin{array}{l}0.9076 \\
0.9661\end{array}$} \\
\hline & $\mathrm{P}$ value intragroup $\|$ & 0.2975 & 0.2850 & \\
\hline \multirow[t]{2}{*}{3} & $\begin{array}{l}\text { Score of sedation } \\
\text { Day } 0 \\
\text { Day } 7\end{array}$ & $\begin{array}{l}0.12 \pm 0.325 \\
0.10 \pm 0.300\end{array}$ & $\begin{array}{l}0.14 \pm 0.347 \\
0.12 \pm 0.325\end{array}$ & \multirow[t]{2}{*}{$\begin{array}{l}0.8769 \\
0.9224\end{array}$} \\
\hline & $\mathrm{P}$ value intragroup $\|$ & 0.6219 & 0.6420 & \\
\hline
\end{tabular}

EPN: Eperisone, TCC: Thiocolchicoside, PCM: Paracetamol, SD: Standard deviation, VAS: Visual Analogue Scale, n: Numbers; Values: Mean \pm SD (otherwise mentioned); *: Statistically significant, $\uparrow:$ Using 2-tailed unpaired t-test, §: Repeated measure ANOVA, $\|$ : paired t- test

Table 4: Adverse effects.

\begin{tabular}{|lll|}
\hline $\begin{array}{l}\text { Type of adverse } \\
\text { effect }\end{array}$ & $\begin{array}{l}\text { Group A } \\
\text { (EPN + } \\
\text { PCM) }\end{array}$ & $\begin{array}{l}\text { Group B } \\
\text { (TCC + } \\
\text { PCM) }\end{array}$ \\
\hline Gastric complaints & $3(6 \%)$ & $3(6 \%)$ \\
\hline Diarrhoea & $0(0 \%)$ & $5(10 \%)$ \\
\hline Headache & $2(4 \%)$ & $1(2 \%)$ \\
\hline Nausea & $1(2 \%)$ & $1(2 \%)$ \\
\hline
\end{tabular}

Eperisone is a muscle relaxant, with a mechanism of action slightly different from that of other muscle relaxants. In addition to inhibition of mono and multi synaptic reflexes in the spinal cord and supra-spinal structures, Eperisone regulates the blood supply to skeletal muscles. ${ }^{11}$ This action is noteworthy since a muscle contracture may compress the small blood vessels and induce an ischemia leading to release of nociceptive compounds. More importantly, Eperisone is devoid of detrimental effects on the central nervous system. ${ }^{11,21}$ Thiocolchicoside and Eperisone are muscle relaxants which mediate muscle relaxation without concomitant sedation and withdrawal phenomenon. ${ }^{1,8}$

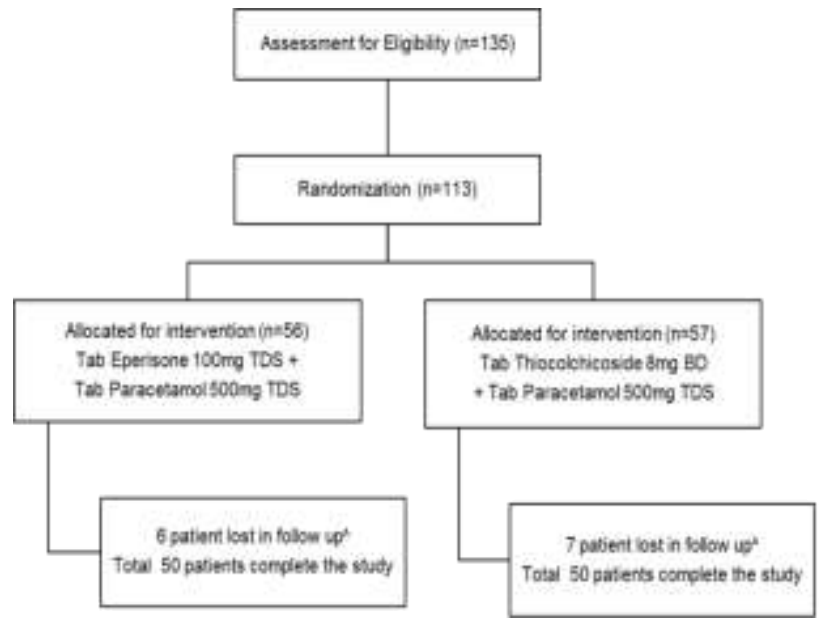

Figure 1: Flowchart showing the run-in of intervention.

In the study carried out by Cabitza et $\mathrm{al}^{11}$ the FFD decreased from $20.31 \mathrm{~cm}$ to $13.86 \mathrm{~cm}$ with Eperisone (p $<0.001$ vs. basal), and from $19.88 \mathrm{~cm}$ to $15.53 \mathrm{~cm}$ with Thiocolchicoside ( $\mathrm{p}<0.001$ vs. basal). Similar results were obtained on day 7 in studies by Silvana et $\mathrm{al}^{12}$ and Chandanwale et $\mathrm{al}^{22}$ using Eperisone. Rao et $\mathrm{al}^{23}$ and Soonawalla et $\mathrm{al}^{24}$ demonstrated same results with Thiocolchicoside $(\mathrm{p}<0.005)$. In the study carried out by 
Cabitza et $\mathrm{al}^{11}$ the VAS score of pain decreased significantly in patients receiving Eperisone and Thiocolchicoside ( $\mathrm{p}<0.001 \mathrm{vs}$. basal in both groups). Frandisco et $\mathrm{al}^{25}$ and Soonawalla et $\mathrm{al}^{24}$ demonstrated a statistically significant decrease in muscle spasm with Eperisone $300 \mathrm{mg}$ and Thiocolchicoside $8 \mathrm{mg}$ respectively. In the study carried out by Cabitza et $\mathrm{al}^{11}$ the pain on pressure was significantly improved in patient treated with Eperisone and Thiocolchicoside. Frandisco et $\mathrm{al}^{25}$ and Ketenci et $\mathrm{al}^{8}$ found that there was lack of significant effect on attention and cognitive function as well as on other normal daily life activities by using Eperisone and Thiocolchicoside respectively.

As a result of paravertebral muscle spasm the flexion of the vertebral column is restricted so FFD is considered to be an index of mobility. In our study Eperisone and Thiocolchicoside caused statistically significant reduction in FFD. At the end of the trial the FFD reduced by $18 \mathrm{~cm}$ in Eperisone group and $17.36 \mathrm{~cm}$ in Thiocolchicoside group from baseline. No significant difference was found in intergroup comparison. Mean VAS score of pain reduced significantly on day 7 . Mean score of pain on VAS reduced by 5.64 scale in Eperisone group as compared to 5.42 scale in Thiocolchicoside group. There was statistically significant reduction in paravertebral muscle tenderness. On day 7 , the spasm relief was $87 \%$ and $88 \%$ in Eperisone and Thiocolchicoside group respectively. In intergroup comparison the difference in VAS score of pain, paravertebral tenderness and spasm relief were not significant. There was no significant increase in sedation, visual as well as auditory reaction times in both groups at the end of the study. The tolerability was better in Eperisone group (few gastrointestinal ADRs) as compared to Thiocolchicoside group.

\section{CONCLUSION}

Eperisone is an effective skeletal muscle relaxant with equivalent efficacy compared to Thiocolchicoside, and has better tolerability in the treatment of patients with low back pain associated with muscle spasm.

\section{ACKNOWLEDGEMENT}

We are grateful to all the staff members of Department of Orthopaedics, Government Medical College and Hospital Aurangabad, for their valuable cooperation.

Funding: No funding sources

Conflict of interest: None declared

Ethical approval: The study was approved by the Institutional Ethical Committee

\section{REFERENCES}

1. Prabhoo R, Keny S, Prabhoo T, Singh A, Rana R. A phase IV observational multi-Centre, open-label study on efficacy and safety of Tolperisone $150 \mathrm{mg}$ in patients with painful muscle spasm associated with degenerative or inflammatory diseases of the musculoskeletal system. JAPI. 2011;59:33-7.

2. Maurits WT, Tony T, Andrea DF, Sherra S, Lex MB. Muscle Relaxants for Nonspecific Low Back Pain. A Systematic Review within the Framework of the Cochrane Collaboration. Spine. 2003;28(17):197892.

3. Nadine EF, Jan H, Peter RC. Taking responsibility for the early assessment and treatment of patients with musculoskeletal pain: a review and critical analysis. Arthritis Research and Therapy. 2012;4(1):205.

4. Andrew RM, Sebastian SB, Sheena D, Henry JM. Low back pain analgesic studies: A methodological mine field. Pain. 2010;149(3):431-4.

5. Roger C, Laurie HH. Clinical Guideline for the evaluation and management of low back pain: Evidence Review. American Pain Society, Publisher Glenview, IL; 2009.

6. Felder M. Medical treatment of muscle spasms and pain. In: Emre M, Mathies H (Eds). Muscle Spasms and Pain. Parthenon Publishing, Carnforth, NJ; 1988:89-96.

7. Burton AK, Balagué F, Cardon G, Eriksen HR, Henrotin Y, Lahad A. European guideline for prevention in low back pain: Nov 2004. European Spine J. 2006;15(2):136-68.

8. Ketenci A, Ozcan E, Karamursel S. Assessment of efficacy and psychomotor performances of thiocolchicoside and tizanidine in patients with acute low back pain. Int J Clin Pract. 2005;59(7):764-70.

9. Pratzel HG, Alken RG, Ramm S. Efficacy and tolerance of repeated oral doses of tolperisone hydrochloride in the treatment of painful reflex muscle spasm: results of a prospective placebocontrolled double-blind trial. Pain.1996;67(2-3):41725.

10. Gold MS. Na+ channel blockers for the treatment of pain: context is everything, almost. Exp Neurol. 2008;210(1):1-6.

11. Cabitza P, Randelli P. Efficacy and safety of eperisone in patients with low back pain: a double blind randomized study. European Review for Medical and Pharmacological Sciences. 2008;12:22935 .

12. Silvana S, Lucia G. Open experience with a new myorelaxant agent for low back pain. Advances in Therapy. 2008;25(10):1010-8.

13. Kocsis P, Farkas S, Fodor L, Bielik N, Thán M, Kolok S, Gere A, Csejtei M, Tarnawa I. Tolperisonetype drugs inhibit spinal reflexes via blockade of voltage-gated sodium and calcium channels. $\mathrm{J}$ of Pharmacology and Experimental Therapeutics. 2005;315(3):1237-46.

14. Quasthoff S, Mockel C, Zieglgänsberger W, Schreibmayer W. Tolperisone: a typical representative of a class of centrally acting muscle relaxants with less sedative side effects. CNS Neuroscience and Therapeutics. 2008;4(2):107-19. 
15. Dulin J, Kovács L, Ramm S, Horvath F, Ebeling L, Kohnen R. Evaluation of sedative effects of single and repeated doses of 50mg and $150 \mathrm{mg}$ tolperisone: Results of a prospective, randomized, double-blind, placebo-controlled trial. Pharmacopsychiatry. 1998;31(4):137-42.

16. Roger C: Pharmacological Management of Low Back Pain, Drugs 2010;70(4):387-402.

17. Savigny P, Kuntze S, Watson P, Underwood M, Ritchie G, Cotterell M, et al. Low back pain: early management of persistent non-specific low back pain Full guideline. National Collaborating Centre for Primary Care (London): Royal College of General Practitioners; May 2009.

18. Guideline for the Low Back Pain: Evidence-Informed Primary Care Management of low back pain, 2 Edition 2011.

19. Berry H, Hutchinson D. Tizanidine and ibuprofen in acute low-back pain: results of a double-blind multicentre study in general practice. J Int Med Res. 1988;16(2):83-91.

20. Sirdalud Ternelin Asia-Pacific Study Group. Efficacy and gastro protective effects of tizanidine plus diclofenac versus placebo plus diclofenac in patients with painful muscle spasms. Curr Ther Res. 1998;59(1):13-22.

21. Tanaka K, Kaneko T, Yamatsu K. Effects of 4'-ethyl2-methyl-3 piperidinoproprio phenone on experimental rigidity and spinal cord activity. Folia Pharmacol Jpn. 1981;77:511-20.

22. Chandanwale AS, Chopra A, Goregaonkar A, Medhi B, Shah V, Gaikwad S et al. Evaluation of eperisone hydrochloride in the treatment of acute musculoskeletal spasm associated with low back pain: A randomized, double-blind, placebo-controlled trial. JPGM. 2010;57(4):278-85.

23. Rao R, Panghate A, Chandanwale A, Sardar I, Ghosh M, Roy $M$ et al. Clinical Comparative Study: Efficacy and Tolerability of Tolperisone and Thiocolchicoside in Acute Low Back Pain and Spinal Muscle Spasticity. ASJ. 2012;6(2):115-22.

24. Soonawalla DF, Joshi N. Efficacy of thiocolchicoside in Indian patients suffering from low back pain associated with muscle spasm. J Indian Med Assoc. 2008;106(5):331-5.

25. Frandisco CR, Ramon VP, Enrique RB, Francisco FB. Effect of two different doses of Eperisone in treatment of acute low back pain. The J of Applied Research. 2009;9(1):23-9.

Cite this article as: Maaz SH, Khandelwal PN, Baig SM, Doifode SM, Ghotkar UM. Evaluation of efficacy and tolerability of eperisone and thiocolchicoside in treatment of low back pain associated with muscle spasm: An open label, prospective, randomized controlled trial. Int J Basic Clin Pharmacol 2016;5:2669-74. 